\title{
Ultrasound-guided percutaneous injection of foam sclerotherapy in management of lower limb varicose veins (pilot study)
}

Omnia A. Seyam ${ }^{*}$, Ahmed S. Elshimy, Gamal Eldine M. Niazi and Mohamed ElGhareeb

\begin{abstract}
Background: Minimally invasive procedures; like ultrasound-guided percutaneous injection of foam sclerotherapy (USGFS) are being the keystone methods in managing lower limb varicose veins and its complications, being advantageable over the surgery as being minimally invasive with better postoperative comfort and immediate cosmetic effect and faster return to full socioeconomic activity. Varicose veins are common problem that affects the quality of life and have a significant cost burden on the health care system. Sclerotherapy (endovenous chemical ablation) destructs the endothelium to induce inflammation and fibrosis and then occlusion of the blood vessel lumen.

Results: The study included 33 diseased limbs of females (64.7\%) and 18 (35.3\%) limbs of males. Of the diseased limbs, 16 (31.3\%) presented with disfigurement, 14 (27.4\%) with pain, 11 (19.6\%) with heaviness, 6 (11.7\%) with edema, and 4 (7.8\%) with non-healed venous ulcer. Twenty-six (50.9\%) diseased limbs show competent saphenofemoral junction (SFJ) while 25 (49.1\%) limbs showed SFJ reflux of variant degrees. All patients underwent direct ultrasound-guided foam sclerotherapy either as the primary therapy in 29 (56.9\%) limbs or as a complementary therapy for residual perforators and varicosities after treatment with other methods of treatment like laser ablation and phlebograph in 22 (43.1\%) limbs. Nine (17.6\%) limbs treated with 2\% polidocanol (Pol.) and 42 (82.3\%) limbs with 3\% Pol. In the 2nd session Doppler follow-up, 35 (68.6\%) limbs showed complete occlusion while 13 (25.5\%) limbs showed partial occlusion, while in the 3rd session Doppler follow-up, 3 (5.9\%) limbs still show partial occlusion while 45 (88.2\%) limbs showed complete occlusion and no recanalization. Forty (78.4\%) limbs addressed marked symptomatic relief while 5 (9.8\%) limbs moderate relief and 3 (5.9\%) cases with mild relief and the other 3 (5.9\%) cases missed follow-up. Twenty-five (49\%) limbs had no complications while 23 (45\%) limbs had different local complications ranging from pain, hyperpigmentation, and superficial thrombophlebitis. Also, we find a statistically significant correlation between the Pol. concentration injected and the symptomatic relief and Doppler US follow-up while there is a borderline correlation between the Pol. concentration injected and the detected complications.
\end{abstract}

Conclusions: The preliminary results revealed ultrasound-guide foam sclerotherapy is an effective and safe treatment for lower limb varicose veins. The concentration of polidocanol injected could be correlated significantly with the symptoms improvement and borderline correlation to the complication rate.

Keywords: USGFS (ultrasound-guided foam sclerotherapy), Varicose veins, Ablation, Polidocanol (Pol.)

*Correspondence: seyamomnia@gmail.com

Radiology Department, Faculty of Medicine, Ain Shams University, Cairo,

Egypt 


\section{Background}

Varicose veins are a common problem that affects the quality of life and have a significant cost burden on the health care system. Varicose veins (VVs) are defined as tortuous, dilated, bulging, superficial veins typically measuring $4 \mathrm{~mm}$ or larger. Other patterns of venous pathology include reticular veins which are less tortuous, flat veins $1-3 \mathrm{~mm}$ diameter, and spider veins which are $1 \mathrm{~mm}$ or less [1]. Varicose veins incidence in the general population is about $40 \%$ with no gender preferences, yet women are more common to address varicose vein-related symptoms than men [2]. Risk factors include family history, pregnancy, prolonged standing, obesity, vascular malformations, old age, and hormone therapy. Varicose veins are more common in Caucasians and Whites compared to Blacks or Asians [1]. Varicose veins' common symptoms are cosmetic disfigurement, heaviness or tension, swelling, aching, restless legs, cramps, tingling, and itching. The prevalence of symptoms tended to increase with age in both sexes [3]. Varicose veins are a complex disease with multifactorial pathogenesis. The exact pathogenesis of the varicose veins is not yet completely understood despite their prevalence. The major cause is venous hypertension due to reflux of blood through incompetent valves or due to venous obstruction [4]. The gold standard method in the assessment of varicose veins is duplex ultrasound. Duplex ultrasound is used to evaluate the anatomical and functional hemodynamic competency of the great saphenous vein (GSV), short saphenous vein (SSV), sapheno-femoral junction (SFJ), saphenopopliteal junction (SPJ), and deep perforators. Venous reflux is diagnosed when a clear reverse flow of blood occurs after a period of forward flow in the

Name:

Date: DOB:

Chief Complaint:

Since beginning of treatment How would you describe the change in your main complaint ? ( Tick one box)

No change (or condition has got worse)

Almost the same, hardly any change at all

A little better, but no noticeable change

Somewhat better, but the change has not made any real difference

Moderately better, and a slight but noticeable elange

Better, and a definite improvement that has made a real and worthwhile difference

A great deal better, and a considerable improvement that has made all the difference

In a similar way, please circle the number below, that matches your degree of change since beginning of treatment

\begin{tabular}{cccccccccccc}
$\begin{array}{c}\text { Much } \\
\text { Better }\end{array}$ & \multicolumn{1}{c}{$\begin{array}{c}\text { No } \\
\text { Change }\end{array}$} \\
\hline 0 & 1 & 2 & 3 & 4 & 5 & 6 & 7 & 8 & 9 & 10
\end{tabular}

Patient's signature: Date:

T)

Reference: Hurst $\mathrm{H}$, Bolton J, Assessing the clinical significance of change scores recorded on subjective outcome measures. J Manipulative Physiol Ther 2004;27:26-35.

PGIC

Very much improved (6-7)

Much improved (4-5)

Minimally improved (2-3)

Worsened or no change $(0-1)$

Frontiers in Neurology | www.frontiersin.org

Fig. 1 PGIC questionnaire and the visual assessment follow-up 


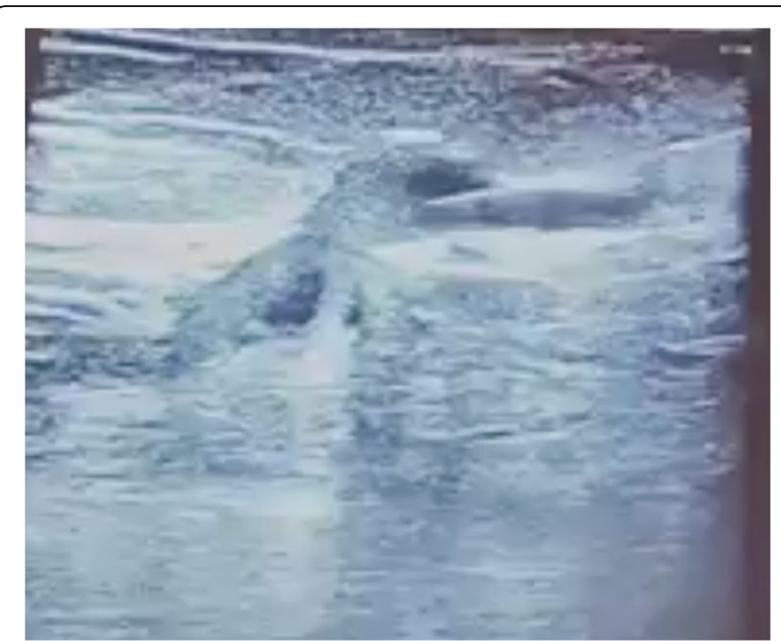

Fig. 2 The US guidance of the needle penetrating the superficial part of the refluxing perforator and injection of the foam causing acoustic shadowing

vein segment. The reflux that lasts for more than 1 $\mathrm{s}$ is usually significant and require intervention. Reflux that lasts $0.5-1 \mathrm{~s}$ is insignificant and usually requires conservative management. Incompetent perforators are assessed in the standing position [2]. Sclerotherapy (endovenous chemical ablation) is using a sclerosant drug that induces inflammation and fibrosis leading to occlusion of the blood vessel lumen through destruction of the endothelium. Liquid sclerotherapy has been used for a long time with a bad reputation of recurrence especially with primary varicose veins (VVs). Yet the foam sclerotherapy has improved the outcome by creating a large contact surface with the sclerosant through the bubbles in the foam. Sclerotherapy has been the primary treatment for isolated incompetent perforators, reticular veins, and recurrent varicose veins after stripping, also in elderly patients unsuitable for surgery, in patients on anticoagulants, and in patients with venous leg ulcers [5]. Sclerosing foam is produced by mixing liquid sclerosant with air. The foam is injected under ultrasound control to monitor its distribution because air bubbles reflect ultrasound and produce acoustic shadowing. Ultrasound-guided foam sclerotherapy (USGFS) is a highly effective technique in sclerosing varicose veins, especially those that are not palpable, including the saphenous veins. However, there are no data to support its use in recurrent varicose veins. USGFS leads to significant improvements in symptoms, quality of life, and increased patient satisfaction with less morbidity and a quicker return to normal activities than surgery [6]. Polidocanol was initially used in the early 1950 s as a local anesthetic that was noticed to cause fibrosis of the veins when intravascular or intradermal injected. It has a high therapeutic index, low incidence of allergic reactions, and post-sclerosis hyperpigmentation [7].

\section{Aim of the work}

Our goal in this study is to highlight the role of ultrasound-guided foam sclerotherapy in varicose veins.

\section{Patients}

A single-arm therapeutic intervention study was done at university hospitals started on September 2018 till September 2019, in which 14 male patients with 18 (35.3\%) diseased limbs and 24 female patients with 33 (64.7\%)

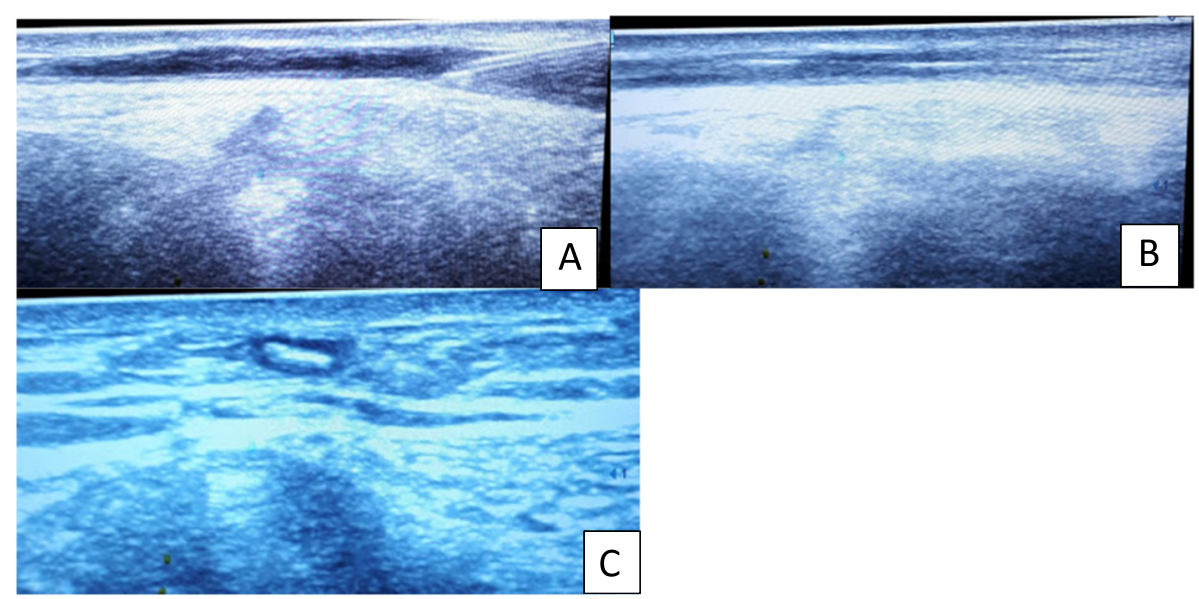

Fig. 3 Superficial varicosities injected with $2 \%$ Pol. with USGFS. a Needle within the vein. $\mathbf{b}$ The acoustic shadowing while injecting the foam. c Transverse view of the vein showing air within the lumen 


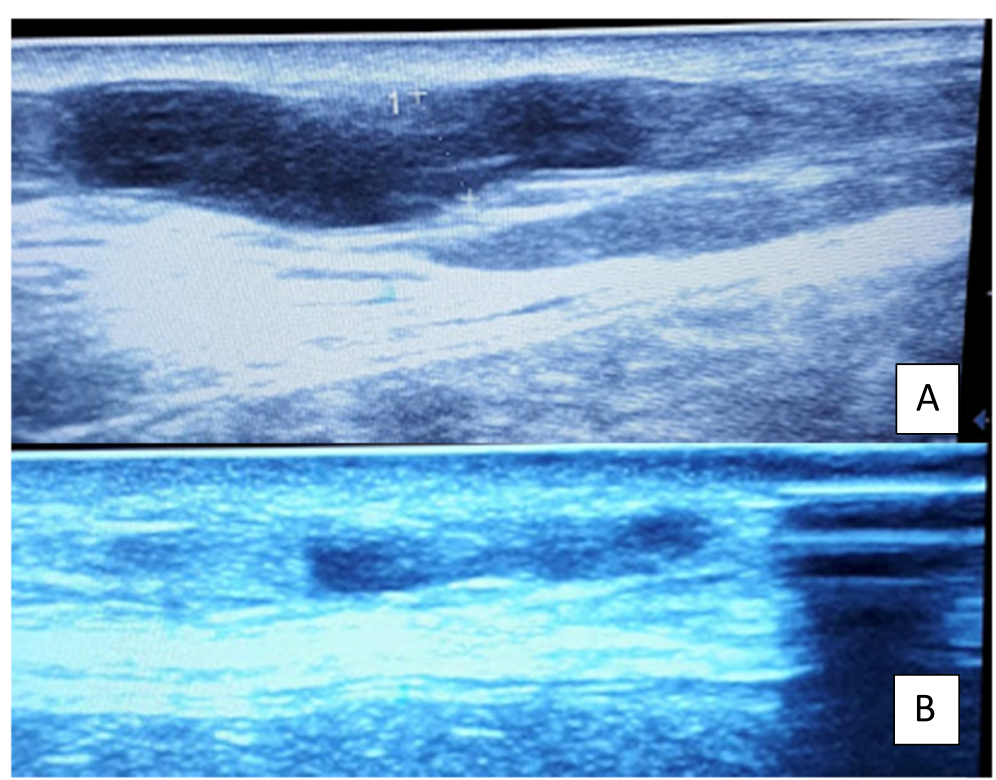

Fig. 4 a First visit ultrasound showing refluxing superficial vein. b Follow-up at the 3rd visit showing diameter changes and echogenic filling

diseased limbs complaining of varicose veins and incompetent perforators with no age predilections were recruited from venous outpatient clinics. Of the diseased limbs, $16(31.3 \%)$ presented with disfigurement, 14 (27.4\%) with pain, 11 (19.6\%) with heaviness, 6 (11.7\%) with edema, and 4 (7.8\%) with non-healed venous ulcer. According to the CEAP (clinical-etiology-anatomicpathological) classification (Fig. 6), 9 (17.6\%) limbs showed C2, 27 (52.9\%) limbs were C3, 11 (21.6\%) limbs were assessed as $\mathrm{C} 4 \mathrm{a}$, and 4 (7.8\%) limbs were C6. Doppler ultrasound assessment of 27 (52.9\%) diseased limbs showed competent SFJ and SPJ while 24 (47.1\%) limbs showed SFJ reflux of variant degrees. Patients with a history of old DVT (deep venous thrombosis) or pulmonary embolism (PE) and patients who are unable to comply with post-treatment compression were excluded. All patients underwent direct ultrasound-guided foam sclerotherapy either alone, $26(56.9 \%)$ limbs, or as a complementary therapy for residual perforators and varicosities after treatment with other methods of treatment like laser ablation and phlebograph rest, 22 (49\%) limbs. Patients were followed up using Doppler ultrasound and PGIC (patient global impression of changes) questionnaire at the fourth and twelfth week PGIC (patient global impression of changes) (Fig. 1) [8-10]. Polidocanol (Pol.) was used as the sclerosant foam, 9 (17.6\%) limbs treated with $2 \%$ Pol. and 42 (82.3\%) limbs with 3\% Pol. Follow-up Doppler findings may be partial occlusion; in which the vein becomes smaller in size yet still showing flow within its lumen or non-occlusion of the entire length of the treated vein or complete occlusion; defined when the vein is smaller and non-compressible with wall thickening and wit a hypoechoic lumen with no flow inside at the entire length of the treated vein while recanalization is defined as the presence of flow in either an antegrade or retrograde direction in a previously occluded vein. Patients who scored $0-1$ on the PGIC scale were considered no improvement, while those who scored 2-3 were considered as mildly improved and 4-5 stands as moderately improved while 6-7 as marked improvement.

\section{Methods}

At the first visit, all patients signed an informed consent which will explain the procedure details and other imaging alternatives.

\section{Pre-procedure preparation}

- No specific medical considerations except DVT.

- The patient is evaluated by US and Doppler to exclude DVT.

- Explain the procedure for the patient and postprocedure risks then obtain informed consent from the patient to start the procedure.

The procedure $[19,20]$

US is performed with Doppler (using GE, lOGIQV5, China Duplex US Machine with high-frequency realtime linear-array transducers $(7-15 \mathrm{MHz})$ ) to identify the refluxing veins and perforators. The whole lower limb is exposed. Then, the patient is standing 


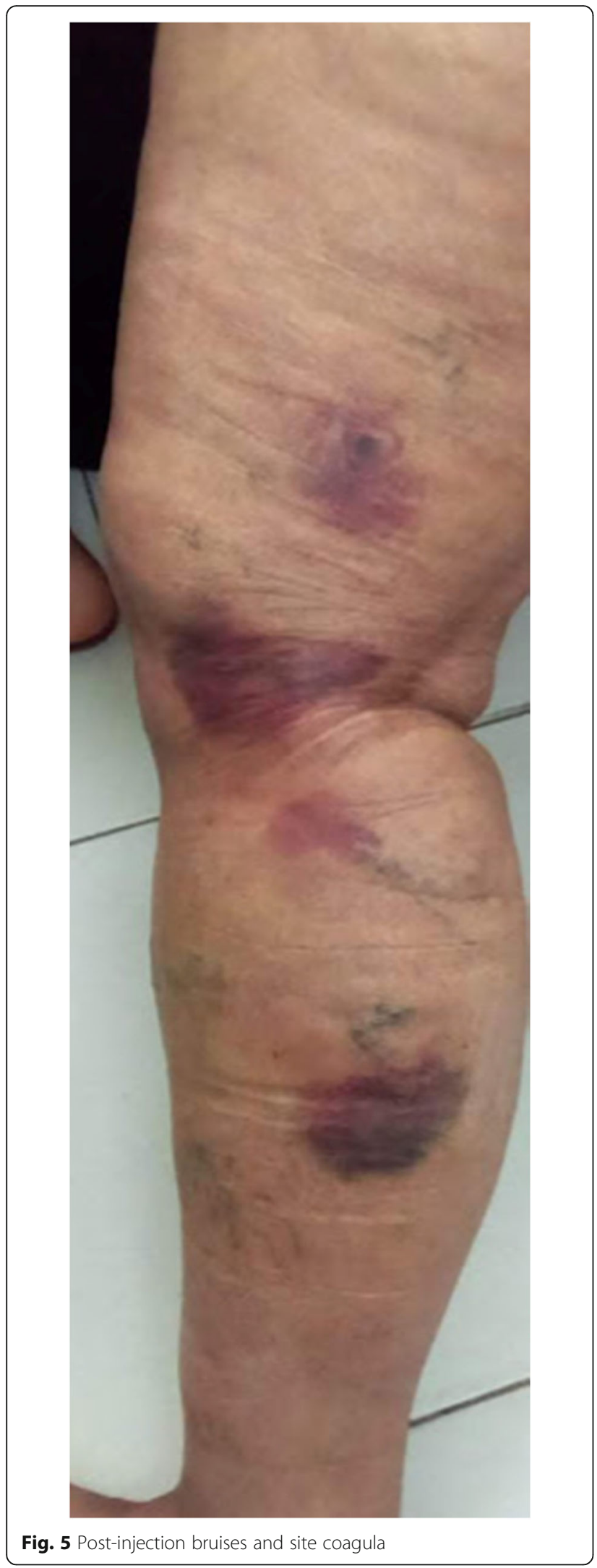

Table 1 Demographic data of the study population

\begin{tabular}{lll}
\hline & & No. of diseased limbs = 51 \\
\hline Sex & Female & $33(64.7 \%)$ \\
& Male & $18(35.3 \%)$ \\
Age & Mean \pm SD & $43.5 \pm 12.4$ \\
& Range & $24-67$ \\
\hline
\end{tabular}

to detect the refluxing sapheno-femoral (SFJ) junction and perforators then mark the site of reflux. In case of refluxing SFJ, the GSV is marked $5 \mathrm{~cm}$ below the SFJ; after marking the site of reflux, the patient return to the supine position and the whole limb is sterilized with betadine and covered with sterile sheets. Then, percutaneously inject local anesthesia using lidocaine $1 \%$ at the targeted area with a maximum dose of $4 \mathrm{mg} / \mathrm{kg}$ of lidocaine. Each $1 \%$ lidocaine ampule contains $10 \mathrm{mg}$ lidocaine. There was no sedation nor general anesthesia is needed. Then, we use US guidance to insert a 20-22 G butterfly cannula at the marked reflux site. Then, we start to infuse the pre-prepared foam sclerotherapy (Fig. 2). Foam sclerotherapy is prepared by polidocanol (POL) ; $2-3 \%$ concentration according to the size of the vein, mixed with air in a ratio of 1:4 (polidocanol to air) propulsion of the mixture within 3 - and 5 - $\mathrm{mL}$ syringes using a 3-way connector. In case of reticular VVs $(5-6 \mathrm{~mm})$, we use $2 \%$ solution with a recommended dosage of $0.1-0.3 \mathrm{~mL}$ IV into each VVs till they disappear yet not to exceed the cumulative dose of $10 \mathrm{~mL}$ per treatment session (Fig. 3). In case of incompetent varicosities of the great saphenous vein system or accessory saphenous veins above and below the knee, use 3\% solution with a recommended dosage of $5 \mathrm{~mL}$ per IV injection, not to exceed $15 \mathrm{~mL} /$ session; repeat treatment may be necessary if the size and extent of the veins to be treated require more than $15 \mathrm{~mL}$, separate treatment sessions by a minimum of 5 days. Then, compression adhesive bandage is applied over the course of

Table 2 Symptomatic and clinical distribution of study population

\begin{tabular}{llll}
\hline Clinical complaint & $\begin{array}{l}\text { Diseased limbs } \\
\text { (no. 51) }\end{array}$ & $\begin{array}{l}\text { Clinical } \\
\text { Classification }\end{array}$ & $\begin{array}{l}\text { Diseased limbs } \\
\text { (no. 51) }\end{array}$ \\
\hline Disfigurement & $16(31.3 \%)$ & C2 & $9(17.6 \%)$ \\
Heaviness & $11(19.6 \%)$ & C3 & $27(52.9 \%)$ \\
Pain & $14(27.4 \%)$ & C4a & $11(21.6 \%)$ \\
Edema & $6(11.7 \%)$ & C6 & $4(7.8 \%)$ \\
$\begin{array}{l}\text { Non-healed } \\
\text { venous ulcer }\end{array}$ & $4(7.8 \%)$ & & \\
\hline
\end{tabular}




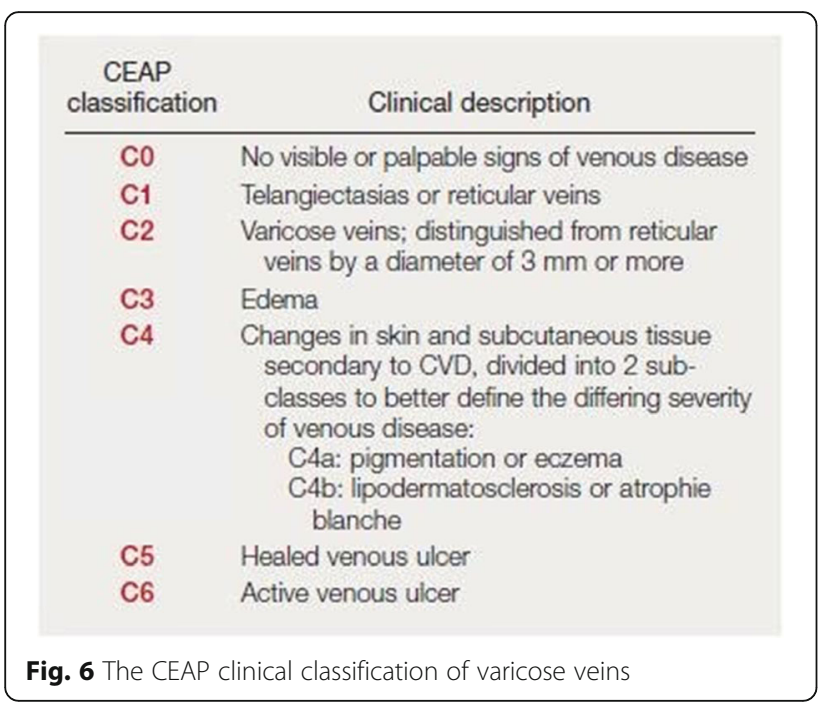

injection then compression stockings. The stockings should be wore for at least 5 to 7 days.

The follow-up is done by Doppler US examination at the 4th and 12th week visits to evaluate the presence of recanalization and the absence of the reflux in the treated veins. If any, reinjection is considered (Fig. 4).

\section{Operative risks and their management}

- Injection site hematoma and irritation. We manage them with hot fomentations over the site of injection (Fig. 5).

- Injection site discoloration due to extravasation of the sclerotherapy. So exclusive IV injection should be considered.

- Injection site pain and warmth. We manage them with paracetamol tablets in a dosage of $1 \mathrm{tab} / 8 \mathrm{~h}$ for 3 days.

- Neovascularization. No specific management.

- Injection site thrombosis and thrombophlebitis could be treated with mild analgesics, like aspirin,

Table 3 Polidocanol concentration injected and the number of sessions

\begin{tabular}{llll}
\hline & & Number & Percentage \\
\hline Pol.\% & $2 \%$ & 9 & 17.6 \\
& $3 \%$ & 42 & 82.3 \\
No. of sessions & 1 & 28 & 54.9 \\
& 2 & 19 & 37.3 \\
& 3 & 1 & 1.9 \\
& 4 & 3 & 5.9 \\
\hline
\end{tabular}

Table 4 The number and percentage of cases subjected to different procedures

\begin{tabular}{llll}
\hline & Number & Percentage \\
\hline Procedure & Direct only & 29 & 56.9 \\
& $\begin{array}{l}\text { Direct complementary therapy for } \\
\text { residual perforators and varicosities } \\
\text { after phlebography }\end{array}$ & 14 & 27.4 \\
$\begin{array}{l}\text { Direct complementary therapy for } \\
\text { residual perforators and varicosities } \\
\text { after laser }\end{array}$ & 8 & 15.7 \\
\end{tabular}

and the use of some type of elastic support usually is sufficient.

- Deep vein thrombosis should be treated with anticoagulants regimen using oral anticoagulants and heparin in the recommended dosage and regimen.

- Recanalization that needs reinjection.

\section{Statistical analysis}

Data were coded and entered using the statistical package SPSS (Statistical Package for the Social Sciences) version 23. Data were summarized by the use of mean, standard deviation, median, minimum, and maximum in quantitative data and using frequency (count) and relative frequency (percentage) for categorical data. Comparisons between the quantitative variables were done using chi-squared and paired tests.

\section{Chi-square test}

$P$ value $>0.05$ indicates non-significant, $P$ value $<0.05$ significant, and $P$ value $<0.01$ highly significant.

\section{Results}

The procedure was done for different categories of the diseased limbs in this study; 33 limbs were for females while 18 limbs were for males. Age ranges from 24 to 67 years old (Table 1 ).

The main complaint was disfigurement in 16 limbs, heaviness in 11 limbs, pain in 14 limbs, edema in 6 limbs, and limbs had non-healed venous ulcers, while clinically, 9 limbs were C2, 27 limbs were C3, 11 limbs were C4a, and 4 limbs were C6 (Table 2) (Fig. 6).

Nine limbs were injected with $2 \%$ polidocanol (Pol.) while 42 limbs were injected with $3 \%$ Pol. Twenty-eight limbs needed 1 injection session while 19 limbs needed 2 sessions, 1 limb need 3 sessions, and 3 limbs need 4 sessions (Table 3).

Twenty-nine diseased limbs were subjected for direct USGFS only therapy of them, 3 missed follow-up; on the 2nd, visit two cases were injected $2 \%$ Pol., and one case on the 3rd visit was injected 3\% Pol., while 
Table $\mathbf{5}$ The 1st visit US findings and the distribution of the varicosities

\begin{tabular}{|c|c|c|c|c|c|}
\hline & & & $\begin{array}{l}\text { No. } \\
\text { of } \\
\text { total } \\
(51)\end{array}$ & Treatment & Percentage \\
\hline \multirow[t]{8}{*}{$\begin{array}{l}\text { US } \\
\text { finding } \\
\text { in the } \\
\text { 1st visit. } \\
\text { Category }\end{array}$} & $\begin{array}{l}\text { Without } \\
\text { SFJ } \\
\text { reflux }\end{array}$ & $\begin{array}{l}\text { Superficial } \\
\text { varicose veins } \\
\text { (>5 mm } \\
\text { diameter) with } \\
\text { no perforator at } \\
\text { thigh lateral } \\
\text { plexus }\end{array}$ & 6 & USGFS & 11.7 \\
\hline & & $\begin{array}{l}\text { GSV varicosities } \\
\text { refluxing thigh } \\
\text { segment with } \\
\text { superficial skin } \\
\text { varicosities and } \\
\text { no perforator } \\
\text { reflux }\end{array}$ & 1 & Phlebograph & 1.9 \\
\hline & & $\begin{array}{l}\text { GSV (great } \\
\text { saphenous) } \\
\text { varicosities with } \\
\text { refluxing } \\
\text { perforators }\end{array}$ & 16 & USGFS & 31.4 \\
\hline & & $\begin{array}{l}\text { SSV (short } \\
\text { saphenous vein) } \\
\text { varicosities; } 2 \\
\text { limbs refluxing } \\
\text { thigh extension } \\
\text { of SSV and } 1 \\
\text { limb with } 2 \\
\text { below knee } \\
\text { perforators }\end{array}$ & 3 & USGFS & 5.9 \\
\hline & & $\begin{array}{l}\text { Refluxing PASV } \\
\text { (posterior } \\
\text { accessory } \\
\text { saphenous vein) } \\
\text { varicosities with } \\
\text { perforators at } 4 \\
\text { below knee } \\
\text { level }\end{array}$ & 2 & USGFS & 3.9 \\
\hline & & $\begin{array}{l}\text { Refluxing AASV } \\
\text { (anterior } \\
\text { accessory } \\
\text { saphenous vein) } \\
\text { varicosities with } \\
3 \text { perforators at } \\
\text { below knee } \\
\text { levels }\end{array}$ & 2 & USGFS & 3.9 \\
\hline & $\begin{array}{l}\text { With SFJ } \\
\text { reflux }\end{array}$ & $\begin{array}{l}\text { Grade } 1 \\
\text { (incompetence } \\
\text { found only } \\
\text { during Valsalva } \\
\text { maneuver on } \\
\text { standing } \\
\text { position) } \\
\text { with perforators }\end{array}$ & 5 & Phlebograph & 9.8 \\
\hline & & $\begin{array}{l}\text { Grade } 2 \\
\text { (incompetence } \\
\text { found during } \\
\text { Valsalva } \\
\text { maneuver on } \\
\text { standing and } \\
\text { supine } \\
\text { positions) with }\end{array}$ & 4 & Phlebograph & 7.8 \\
\hline
\end{tabular}

Table 5 The 1st visit US findings and the distribution of the varicosities (Continued)

\begin{tabular}{|c|c|c|c|}
\hline & $\begin{array}{l}\text { No. } \\
\text { of } \\
\text { total } \\
(51)\end{array}$ & Treatment & Percentage \\
\hline $\begin{array}{l}\text { refluxing } \\
\text { perforators }\end{array}$ & & & \\
\hline $\begin{array}{l}\text { Grade } 3 \\
\text { (incompetence } \\
\text { found } \\
\text { spontaneously } \\
\text { on standing } \\
\text { position) with } \\
\text { refluxing } \\
\text { perforators and } \\
\text { lateral plexus } \\
\text { thigh } \\
\text { varicosities }\end{array}$ & 12 & $\begin{array}{l}8 \text { of them } \\
\text { laser } \\
4 \text { of them } \\
\text { phlebograph }\end{array}$ & 23.5 \\
\hline
\end{tabular}

25 diseased limbs were subjected for direct USGFS for the residual varicosities after previous treatment with other methods co-add to USGFS: 17 limbs for phlebography and USGFS direct injection and 8 limbs for endovenous laser ablation in combination with USGFS for residual lower limb perforators and varicosities (Table 4).

In the 1st visit US evaluation, $30(58.8 \%)$ limbs showed variable degrees of SFJ incompetence while 21 (41.2\%) of limbs showed competent SFJ. The distribution of the varicosities is shown in Table 5 while Table 6 shows the diameter of the treated perforators.

At the 2nd visit US follow-up, 35 limbs showed complete occlusion while 13 limbs showed partial occlusion. At the 3rd visit US follow-up, 3 limbs still had partial occlusion, 4 limbs showed complete occlusion, and 41 limbs did not recanalize. Partial occlusion; in which the vein becomes smaller in size yet still showing flow within its lumen or nonocclusion of the entire length of the treated vein at the 2nd US follow-up visit, while complete occlusion is when the vein is smaller and noncompressible with wall thickening and with the hypoechoic lumen with no flow inside at the entire length of the treatment at the 2nd US follow-up visit and recanalization is the presence of flow in either an antegrade or retrograde direction in a previously occluded vein (at the 3rd US follow-up visit) $[11,12]$ (Table 7).

Forty cases showed marked symptom relief and 5 limbs showed moderate relief while 3 limbs showed mild

Table 6 The caliber of the treated perforators

\begin{tabular}{llll}
\hline Caliber of perforator & No perforators & 9 & $17.6 \%$ \\
& $5-10 \mathrm{~mm}$ & 23 limbs & $45 \%$ \\
& $10-15 \mathrm{~mm}$ & 19 limbs & $37.3 \%$ \\
\hline
\end{tabular}


Table 7 The ultrasound follow-up findings in the 2nd and 3rd visits

\begin{tabular}{llll}
\hline & & Number & Percentage \\
\hline US finding in 2nd visit & Complete & 35 & 68.6 \\
& Partial & 13 & 25.5 \\
& Missed follow-up & 3 & 5.9 \\
US finding 3rd visit & Partial & 3 & 5.9 \\
& Complete & 10 & 19.6 \\
& No recanalization & 35 & 68.6 \\
& Missed follow-up & 3 & 5.9 \\
\hline
\end{tabular}

relief and 3 limbs missed follow-up. The study showed a statistically significant relation between the concentration of Pol. injected and the symptom relief ( $P$ value 0.025663) (Table 8).

There is no significant correlation between the symptom's relief and either USGFS used alone or as a commentary therapy to residual varicosities after laser or phlebography ( $P$ value 0.859806$)$ (Table 9).

As regards the complications, it shows borderline significance correlation as regarding the concentration of the Pol. injected with ( $P$ value 0.05395) (Table 10).

The higher the concentration the faster the occlusion of the vessel on the 2 nd and 3 rd visit US follow-up ( $P$ value 0.004281 ) (Table 11).

Also, there is no significant correlation as regards the follow-up results and injecting USGFS alone or as a complementary therapy to residual varicosities after laser or phlebograph injection ( $P$ value 0.139341$)$ (Table 12).

\section{Illustrated cases}

\section{Case 1}

History: A 45-year-old female patient teacher, with left lower limb throbbing pain and clinically both limbs were C4a.

US doppler examination: No reflux at SFJ (saphenofemoral junction) yet the left leg shows a $5 \mathrm{~mm}$ incompetent perforator at the below knee level over the

Table 8 The correlation between polidocanol concentration injected and the symptomatic correlation

\begin{tabular}{lllllll}
\hline $\begin{array}{l}\text { Symptom } \\
\text { improvement }\end{array}$ & $\begin{array}{l}\text { Marked } \\
(N, 40)\end{array}$ & $\begin{array}{l}\text { Moderate } \\
(N, 5)\end{array}$ & $\begin{array}{l}\text { Mild } \\
(N, 3)\end{array}$ & $\begin{array}{l}\text { Test } \\
\text { value }\end{array}$ & $P$ value & Significance \\
\hline $\begin{array}{l}\text { Pol. 2\% } \\
\text { (no. 7) }\end{array}$ & 4 & 1 & 2 & 7.3254 & 0.025663 & Significant \\
$\begin{array}{l}\text { Pol. 3\% } \\
\text { (no. 41) }\end{array}$ & 36 & 4 & 1 & & & \\
\hline
\end{tabular}

Table 9 The correlation between the method of injection either direct USGFS alone or in combination with other methods and the symptomatic correlation

\begin{tabular}{lllllll}
\hline $\begin{array}{l}\text { Symptoms } \\
\text { improvement }\end{array}$ & $\begin{array}{l}\text { Marked } \\
(N, 40)\end{array}$ & $\begin{array}{l}\text { Moderate } \\
(N, 5)\end{array}$ & $\begin{array}{l}\text { Mild } \\
(N, 3)\end{array}$ & $\begin{array}{l}\text { Test } \\
\text { value }\end{array}$ & $P$ value & Significance \\
\hline Direct (no. 26) & 21 & 3 & 2 & 0.3021 & 0.859806 & $\begin{array}{l}\text { Not } \\
\text { significant }\end{array}$ \\
$\begin{array}{l}\text { Direct as } \\
\text { complementary } \\
\text { therapy (no. 22) }\end{array}$ & 19 & 2 & 1 & & & \\
\hline
\end{tabular}

distribution of the GSV (great saphenous vein) with competent SFJ (sapheno-femoral junction).

Procedure: Direct USGFS alone using 3\% Pol. foam.

The 2nd US visit: Complete occlusion.

The 3rd US visit: Both perforators were completely occluded and no recanalization was recorded.

Complications: The patient had pain while injecting the Pol. at the site of injection; it lasts for 1 day after the sessions and relieved with NSAID (non-steroidal antiinflammatory).

Symptoms follow-up: The patient had marked symptomatic improvement at this limb.

Figure 7, before and after USGFS with 3\% Pol. shows complete obliteration of the varicosities.

\section{Case 2}

History: A 65-year-old male patient manual worker, with left lower limb throbbing pain and right lower limb disfigurement. Clinically both limbs were C4a.

US Doppler examination: No reflux at SFJ (saphenofemoral junction) yet the left leg shows 1 incompetent perforator at below knee level over the distribution of the GSV (great saphenous vein) which is $5 \mathrm{~mm}$ in diameter.

Procedure: Direct USGFS alone using 2\% Pol. foam.

The 2nd US visit: Complete occlusion of the perforator.

The 3rd US visit: Completely occluded and no recanalization was recorded (Fig. 2).

Complications: Nothing.

Symptoms follow-up: Marked relief

Figure 8 Refluxing perforator before USGFS and after, showing complete occlusion of the perforator

Table 10 The correlation between the polidocanol concentration injected and the complications

\begin{tabular}{llllll}
\hline & $\begin{array}{l}\text { Nothing } \\
(N, 25)\end{array}$ & $\begin{array}{l}\text { Complications } \\
(N, 23)\end{array}$ & $\begin{array}{l}\text { Test } \\
\text { value }\end{array}$ & $P$ value & Significance \\
\hline $\begin{array}{l}\text { Pol 2\% } \\
\text { (no. 7) }\end{array}$ & 6 & 1 & 3.7141 & 0.053956 & $\begin{array}{l}\text { Not } \\
\text { significant }\end{array}$ \\
$\begin{array}{l}\text { Pol 3\% } \\
\text { (no. 41) }\end{array}$ & 19 & 22 & & & \\
\hline
\end{tabular}


Table 11 Relation between polidocanol injected and the US follow-up findings in both 2nd and 3rd sessions

\begin{tabular}{ccccccc}
\hline Significance & $\begin{array}{l}P \\
\text { value }\end{array}$ & $\begin{array}{l}\text { Complete } \\
\text { occlusion } \\
(n \text { 35) }\end{array}$ & $\begin{array}{l}\text { Test } \\
\text { value }\end{array}$ & $P$ value & Significance \\
$\begin{array}{c}\text { Pol 2\% } \\
\text { (no. 6) }\end{array}$ & 5 & 1 & 10.9865 & .000918 & significant \\
$\begin{array}{c}\text { Pol 3\% } \\
\text { (no.42) }\end{array}$ & 8 & 34 & & & & \\
$\begin{array}{l}\text { 3rd visit } \\
\text { US finding }\end{array}$ & $\begin{array}{l}\text { Partial } \\
(n \text { 3) }\end{array}$ & $\begin{array}{l}\text { Complete } \\
\text { occlusion } \\
(n, 10)\end{array}$ & $\begin{array}{l}\text { No } \\
\text { recanalization } \\
(n, 35)\end{array}$ & $\begin{array}{l}\text { Test } \\
\text { value }\end{array}$ & $P$ value & Significance \\
$\begin{array}{c}\text { Pol 2\% } \\
\text { (no. 6) }\end{array}$ & 2 & 3 & 1 & 1 & 0.000996 & Significant \\
$\begin{array}{c}\text { Pol 3\% } \\
\text { (no. 42) }\end{array}$ & 1 & 7 & 34 & 34 & & \\
\hline
\end{tabular}

\section{Case 3}

History: A 36-year-old female housewife complained of heaviness at the left leg. Clinically C4a.

US Doppler examination: Sever reflux at SFJ (sapheno-femoral junction) grade 3 with 2 below knee perforators along the distribution of the GSV (great saphenous vein); one is $8 \mathrm{~mm}$ the other is $10 \mathrm{~mm}$ in diameter.

Procedure: Laser ablation of the GSV followed with direct USGFS using 3\% Pol. foam.

The 2nd US visit: Complete occlusion of the perforator.

The 3rd US visit: Completely occluded and no recanalization was recorded.

Complications: Hyperpigmentation at the injection site.

Symptoms follow-up: Marked relief.

\section{Case 4}

History: 26-year-old female housewife complained of edema at both legs. Clinically C3.

US Doppler examination: Dilated refluxing ovarian veins with secondary moderate reflux of the SFJ (grade 2 with 1 below knee perforators along the distribution of the GSV measuring $8 \mathrm{~mm}$ in diameter and refluxing thigh extension of the short saphenous vein.

Procedure: Transjugular catheter-directed embolization of the left ovarian vein using histoacryl then followed with direct USGFS using 3\% Pol. foam.

The 2nd US visit: Complete occlusion of the perforator and partial occlusion of the thigh extension (Fig. 8).
The 3rd US visit: Completely occluded and no recanalization was recorded.

Complications: No complications (Fig. 9).

Symptoms follow-up: Marked relief.

\section{Discussion}

In our pilot study, we find that the success occlusion rate is $80.3 \%$ (41 limbs out of 51) in concomitant. Smith [13] found that $82 \%$ of cases show no recanalization and complete obliteration in the follow-up. On the other side, in our study, we had no recanalization at the short spectrum follow-up of 12 weeks while Bradbury et al. [14] had $8.7 \%$ recanalization rate over a follow-up period of 28 months. In our study, complete non-recanalized occlusion in cases which had direct USGFS only injection is $39.2 \%$, while Gibson and Gunderson [15] using 2\% Pol. showed 23\% of limbs show complete occlusion of the GSV trunks. Darvall et al. [12] show complete occlusion in the range from 93 to $98 \%$ of treated legs, and recanalization occurred in $9-12 \%$ of cases with 12-month follow-up. Figueiredo et al. [16] using $3 \%$ polidocanol showed $78 \%$ of cases show complete occlusion.

Regarding the complications, $49 \%$ of limbs show no complications (25 limbs), and serious complications like anaphylaxis, DVT, and pulmonary embolism did not occur with our study, while $13.7 \%$ of limbs (7 limbs) showed superficial thrombophlebitis, $5.9 \% \quad(3$ limbs) showed hyperpigmentation, $19.6 \%$ (10 limbs) had pain, $5.9 \%$ (3 limbs) had injection site coagula, and $5.9 \%$ (3 cases) missed the follow-up. On the other hand, Cavezzi and Parsi [17] find significant complications which include anaphylactic/anaphylactoid reactions (very rare), deep vein thrombosis (1$3 \%)$, stroke $(0.01 \%)$, superficial venous thrombosis (4.4\%), tissue necrosis (variable frequency), edema $(0.5 \%)$, and nerve damage $(0.2 \%)$. Cosmetic complications include telangiectatic matting (15-24\%) and pigmentation (10-30\%). Bradbury et al. [14] using 3\% STS (sodium tetrasulphate) showed $0.4 \%$ of cases had DVT and pulmonary embolism and $0.5 \%$ of cases had transient visual disturbance.

Concerning the clinical improvement, in our study $80.4 \%$ of cases (41 limbs of 51 ) show marked improvement, $7.8 \%$ of cases show moderate improvement (4 limbs), $5.9 \%$ of cases show mild improvement (3limbs). Osman et al. [18] using 2\% Pol. showed $86.7 \%$ of cases

Table 12 Relation between procedure and the US follow-up findings in both 2nd and 3rd sessions

\begin{tabular}{lllll}
\hline 3rd visit US finding & Partial $(n, 3)$ & Complete occlusion $(n, 10)$ & No recanalization $(n, 35)$ & Test value \\
\hline Direct (no. 26) & 1 & 3 & 22 & Significance \\
Direct as complementary therapy (no. 22) & 2 & 7 & 13 & Not significant \\
\hline
\end{tabular}




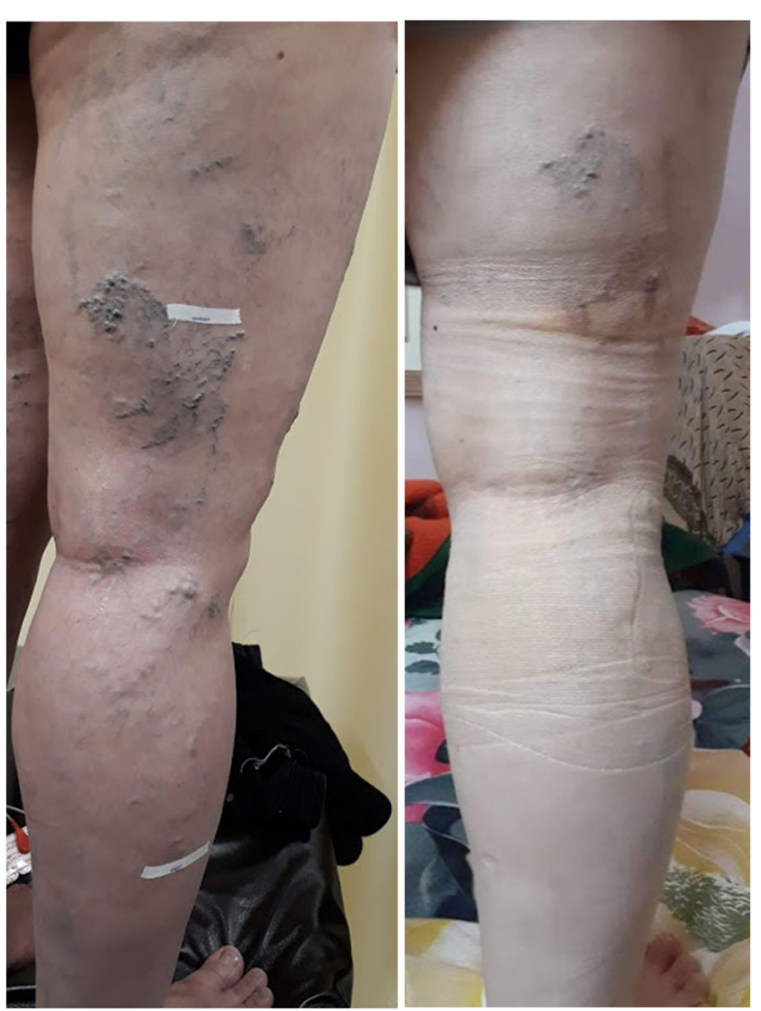

Fig. 7 Before and after USGFS with 3\% Pol. shows complete obliteration of the varicosities. The white marks indicate the site of the refluxing perforators

show marked improvement and $6.7 \%$ of cases show no improvement.

\section{Conclusion}

The preliminary results revealed ultrasound-guide foam sclerotherapy is an effective and safe treatment for lower limb varicose veins. The concentration of polidocanol injected could be correlated significantly with the symptoms improvement and borderline correlation to the complication rate.

\section{Recommendations}

Further extended blind randomized trial on a larger group of patients need to be done to correlate the exact effect of Pol.\% polidocanol concentration on the complication rate. Also, more combined methods with direct

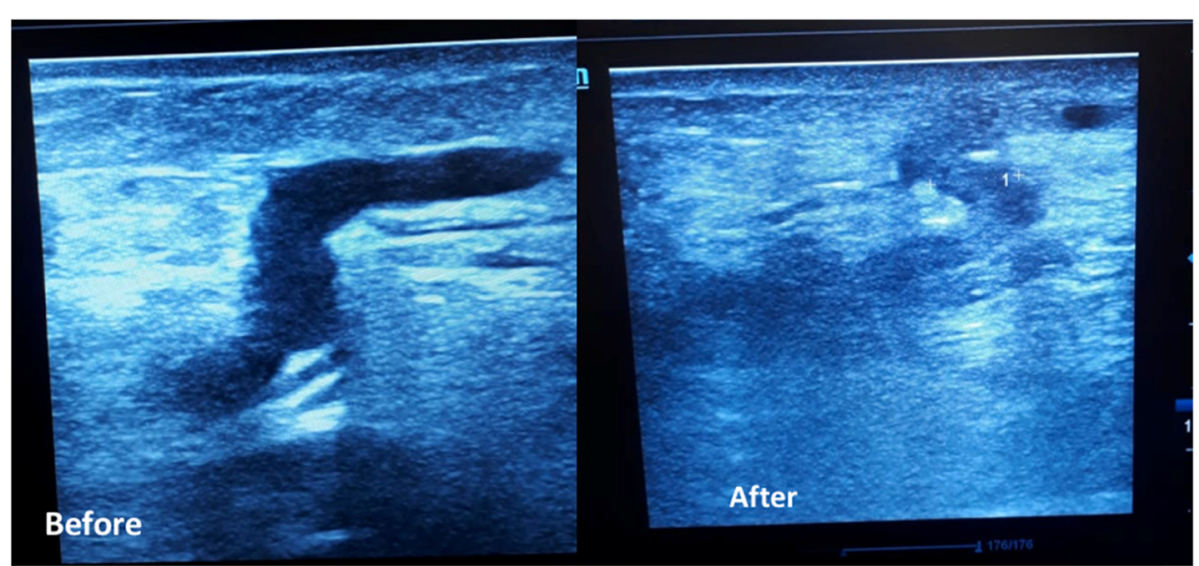

Fig 8 Refluxing perforator before USGFS and after showing complete occlusion of the perforator 


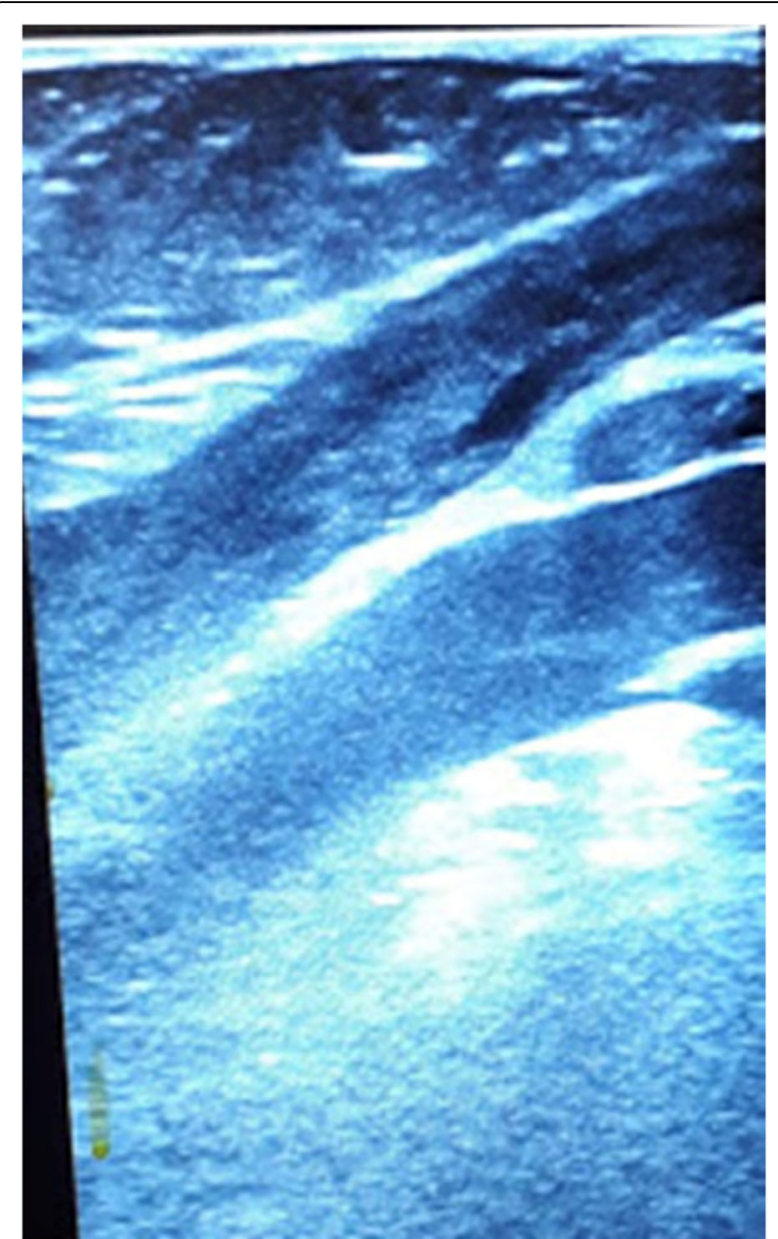

Fig. 9 Refluxing short saphenous vein thigh extension after 3\% Pol. USGFS injection showing partial occlusion

USGFS is needed to detect the real effect on complications and outcome and a prolonged period of follow-up to show the recanalization rate.

\section{Abbreviations}

USGFS: Ultrasound-guided foam sclerotherapy; Pol.: Polidocanol; Pol.\%: Polidocanol concentration; STS: Sodium tetrasulfate; PGIC: Patient global impression of changes

\section{Acknowledgements}

\section{Not applicable}

\section{Reference Number of approvals}

\section{Not applicable.}

All patients included in this study gave written informed consent to participate in this research.

\section{Authors' contributions}

OS is the corresponding author and contributed by doing the ultrasoundguided foam sclerotherapy and Doppler ultrasound examination before and after the USGFS for all the patients enrolled in the study and interpretation of the results and helped in editing the manuscript and reference collection. AE contributed to the data collection and analysis, reviewing the literature, shared in statistical analysis, helped in manuscript editing. GN revised the references and shared in manuscript revision and writing. ME revised the manuscript and the selected images. All authors have read and approved the final version submitted.

\section{Funding}

No funds, sponsorship, or financial support to be disclosed.

\section{Availability of data and materials}

The datasets used and/or analyzed during the current study are available from the corresponding author on reasonable request.

\section{Ethics approval and consent to participate}

This study was approved by the Research Ethics Committee of the Faculty of Medicine at Ain shams University in Egypt.

\section{Consent for publication}

All patients included in this research gave written informed consent to publish the data contained within this study.

\section{Competing interests}

The authors declare that they have no competing interests.

Received: 4 June 2020 Accepted: 22 July 2020

Published online: 01 September 2020

\section{References}

1. Tafur Alfonso J., Suman Rathbun, Vascular medicine: a companion to Braunwald's heart disease (Second Edition), 2013; 639-651

2. Robertson LA, Evans CJ, Lee AJ, Allan PL, Ruckley CV, Fowkes FGR (2014) Incidence and risk factors for venous reflux in the general population: Edinburgh Vein Study. European Journal of Vascular and Endovascular Surgery August 48(2):208-2014

3. Andrew B, Christine E, Paul A, Amanda L, Vaughan RC, Fowkes FGR (1999) What are the symptoms of varicose veins? Edinburgh vein study cross sectional population survey. BMJ 318:353

4. Jacobs BN, Andraska EA, Obi AT, Wakefield TW (2017) Journal of Vascular Surgery: Venous and Lymphatic Disorders 5(3):460-467

5. Kakkos SK, Bountouroglou DG, Mustafa A, Evi K, Marios D, George G (2006) Effectiveness and safety of ultrasound-guided foam sclerotherapy for recurrent varicose veins: immediate results. Journal of Endovascular Therapy 13:357-364

6. Bradbury AW, Gareth B, RGN PK, Darvall Katy A, Adam Donald J (2010) Ultrasound-guided foam sclerotherapy is a safe and clinically effective treatment for superficial venous reflux. Journal of Vascular Surgery October 52(4):939-945

7. Collini FJ (2000) $0.5 \%$ Polidocanol for treatment of varicose veins. Aesthetic Surgery Journal 20(1):19-25

8. Farrar JT, Young JP, LaMoreaux L, Werth JL, Poole MR (2001) Clinical importance of changes in chronic pain intensity measured on an 11-point numerical pain rating scale. Pain 94(2):149-158. https://doi.org/10.1016/ s0304-3959(01)00349-9

9. Villiger, M., Liviero, J., Awai, L., Stoop, R., Pyk, P., Clijsen, R., ... Bolliger, M. (2017). Home-based virtual reality-augmented training improves lower limb muscle strength, balance, and functional mobility following chronic incomplete spinal cord injury. Frontiers in Neurology, 8.doi:https://doi.org/ 10.3389/fneur.2017.00635

10. Hurst $\mathrm{H}$, Bolton J (2004) Assessing the clinical significance of change scores recorded on subjective outcome measures. Journal of Manipulative and Physiological Therapeutics 27(1):26-35. https://doi.org/10.1016/j.jmpt.2003. 11.003

11. Vinit Baliyan, Shahein Tajmir, Sandeep S. Hedgire, Suvranu Ganguli, Anand M. Prabhakar. Lower extremity venous reflux cardiovascular diagnosis and therapy. 2016 Dec; 6(6): 533-543. doi: https://doi.org/10.21037/cdt.2016.11. 14 PMCID: PMC5220199.

12. Darvall KAL, Bate GR, Adam DJ, Silverman SH, Bradbury AW (2011) Duplex ultrasound outcomes following ultrasound-guided foam sclerotherapy of symptomatic recurrent great saphenous varicose veins. European Journal of Vascular and Endovascular Surgery 42(1):107-114. https://doi.org/10.1016/j. ejvs.2011.03.010

13. Smith PC (2006) Chronic venous disease treated by ultrasound guided foam sclerotherapy. European Journal of Vascular and Endovascular Surgery 32(5): 577-583. https://doi.org/10.1016/j.ejvs.2006.04.033

14. Bradbury AW, Bate G, Pang K, Darvall KA, Adam DJ (2010) Ultrasoundguided foam sclerotherapy is a safe and clinically effective treatment for 
superficial venous reflux. Journal of Vascular Surgery 52(4):939-945. https:// doi.org/10.1016/j.jvs.2010.04.077

15. Gibson K, Gunderson K (2018) Liquid and foam sclerotherapy for spider and varicose veins. Surgical Clinics of North America 98(2):415-429. https://doi. org/10.1016/j.suc.2017.11.010

16. Figueiredo M, Araújo S, Barros N, Miranda F (2009) Results of surgical treatment compared with ultrasound-guided foam sclerotherapy in patients with varicose veins: a prospective randomised study. European Journal of Vascular and Endovascular Surgery 38(6):758-763. https://doi.org/10.1016/j. ejvs.2009.07.015

17. Cavezzi A, Parsi K (2012) Complications of foam sclerotherapy. Phlebology. The Journal of Venous Disease 27(1_suppl):4651. https://doi.org/10.1258/ phleb.2012.012s09

18. Osman NMM, Hameed AAA, El Sherief MAF (2015) The role of ultrasound guided foam sclerotherapy in treatment of truncal varicose veins. The Egyptian Journal of Radiology and Nuclear Medicine 46(4):981-986. https:// doi.org/10.1016/j.ejrnm.2015

19. King JT, O'Byrne M, Vasquez M, Wright D (2015) Treatment of truncal incompetence and varicose veins with a single administration of a new polidocanol endovenous microfoam preparation improves symptoms and appearance. European Journal of Vascular and Endovascular Surgery 50(6):784-793

20. Paty J, Turner-Bowker DM, Elash CA, Wright D (2016) The WSymQ ${ }^{\oplus}$ instrument: use of a new patient-reported outcome measure for assessment of varicose vein symptoms. Phlebology: The Journal of Venous Disease 31(7):481-488. https://doi.org/10.1177/0268355515595193

\section{Publisher's Note}

Springer Nature remains neutral with regard to jurisdictional claims in published maps and institutional affiliations.

\section{Submit your manuscript to a SpringerOpen ${ }^{\circ}$ journal and benefit from:}

- Convenient online submission

- Rigorous peer review

- Open access: articles freely available online

- High visibility within the field

- Retaining the copyright to your article

Submit your next manuscript at $\boldsymbol{\nabla}$ springeropen.com 